\title{
O povo Indígena Karajá de Aruanã/GO: ressignificações socioculturais
}

\author{
The Karajá people from Aruanã, GO sociocultural \\ resignifications
}

\section{Les populations Autochtones Karajá de Aruanã / GO: resignifications socioculturel}

\author{
Lorranne Gomes da Silva \\ Universidade Estadual de Goiás - Câmpus Cora Coralina \\ lorrannegomes@gmail.com \\ Sélvia Carneiro de Lima \\ Instituto Federal de Goiás - Câmpus Inhumas \\ selvia_lima@yahoo.com.br
}

\begin{abstract}
Resumo
Este artigo traz discussões sobre as reconfigurações socioculturais no modo de vida do povo Karajá de Aruanã-GO, que foram intensificadas nas últimas décadas. A língua materna, as músicas, a reorganização socioespacial, modificações nos hábitos alimentares e no processo educativo de crianças e jovens, dentre outros, são alguns exemplos que tiveram com a situação de contato, alterações significativas e que merecem reflexões. É possível que as tradições seculares vivenciadas em um ambiente cada vez mais moderno, seja vivenciada pelas gerações mais recentes? As diversas manifestações culturais que identificam os Karajá são traços que em Aruanã tem sido fortalecidos, modificados ou abandonados? Essas são, portanto, algumas das questões que desafiam os estudiosos da temática e os próprios povos indígenas. A pesquisa de caráter qualitativo foi desenvolvida a partir de levantamentos bibliográficos, trabalho de campo, diário de campo e entrevistas. Autores como Lima (2010a e 2010b), Haesbaert (1999), Rocha (2008), foram fundamentais para estabelecer a base teórico-metodológico da pesquisa.

Palavras-chave: Povo Indígena Karajá de Aruanã-GO. Turismo. Ressignificações socioculturais.
\end{abstract}

\footnotetext{
Abstract

This article brings discussions on cultural reconfigurations in the life style of the Karaja people from the city of Aruanã/Goiás, intensified in the past decades. Their
} 
mother tongue, music, socialspatial reorganization, changes in food intake habits, children's and adult's educational process, among others, are examples that illustrate the contact situation, significant changes that deserve reflection. Are secular traditions experienced in a fast-changing environment likely to be experienced by younger generations? Has the diverse cultural output that identifies the Karajás become stronger, modified or abandoned? These are problems that challenge scholars and indigenous people. This qualitative-oriented research was carried out with bibliographic research, field work, field journal and interviews. Authors such as Lima (2010a, 2010b), Haesbaert (1999) and Rocha (2008) have been fundamental to establish the theoretical methodological framework for the research.

Keywords: Karajá de Aruanã Indigenous People. Tourism. Sociocultural Resignification.

\begin{abstract}
Résumé
Cet article apporte des discussions sur les reconfigurations socio-culturelles dans le mode de vie Karajá Aruanã-GO qui se sont intensifiées au cours des dernières decades. La langue maternelle, les chansons, la réorganisation sociale et spatiale, les changements dans les habitudes alimentaires et dans le procès éducatif des enfants et des jeunes, entre autres, sont quelques exemples qu'ils ont eu en contact avec la situation et les changements importants qui méritent une réflexion. Il est possible que les traditions séculaires expérimentée dans un environnement de plus en plus moderne, être connu par les générations suivantes? Les diverses expressions culturelles qui identifient les Karajás sont traits que en Aruanã ont été renforcée, modifié ou abandonné? Ce sont donc quelques problèmes que confrontent les chercheurs du thème et les peuples autochtones eux-mêmes. La recherche qualitative a été developée à partir des enquêtes de la littérature, le travail de terrain, journal sur le terrain et des intrevues. Des auteurs tels que Lima (2010a et 2010b), Haesbaert (1999), Rocha (2008), ont contribué à établir les bases théoriques et méthodologiques de la recherche.

Mots-clés: Indigène Karajà Aruanã-GO. Tourisme. Réinterprétation Socioculturelle.
\end{abstract}

\title{
Introdução
}

O que significa ser indígena no século XXI com vidas entrelaçadas na dinâmica do tempo/espaço global e de um capitalismo avassalador? Como conciliar tradições seculares em um ambiente cada vez mais moderno? Estas questões são algumas das balizas de inquietações que moveu a elaboração da presente discussão.

Tendo como base os Karajá de Aruanã-GO, um dos cinco povos indígenas que compõe a diversidade étnica do território goiano no tempo atual, procurar-se-á verificar como este povo diante das pressões externas provocadas pelo contato interétnico com os não-indígenas foram traçando estratégias de reelaboração de sua cultura para continuarem existindo em seus próprios termos mesmo cerceado por interesses econômicos divergentes daquilo que as tradições indígenas os ensinaram, como o uso coletivo da terra, o valor espiritual (e não mercadológico) dos elementos que compõe a natureza, terra, água, fauna, flora.

Habitantes tradicionais das margens do rio Araguaia e de seus afluentes, os Karajá, desde a década de 1970, tem enfrentado a crescente pressão gerada pela disputa 
de seus territórios tradicionais em detrimento do interesse suscitado, sobretudo, pelas atividades pecuária e turística.

A pesquisa desenvolvida apontou que o contato interétnico e a inserção dos Karajá nas demandas mercadológicas do turismo, pecuária e da vida urbana culminou com várias modificações e ressignificações da cultura desse povo, como a redução dos falantes da língua Karajá; o ensino e aprendizado de músicas tradicionais; a organização do trabalho; as mudanças nos hábitos alimentares com a introdução de bebidas como as alcoólicas e gaseificadas; o consumo de sal, açúcar e óleo; introdução da educação escolar no processo educativo das crianças e jovens, dentre outros.

O texto está organizado em três partes, a primeira apresenta o povo indígena Karajá do município de Aruanã/GO, sujeitos pesquisados. A segunda reflete sobre a dualidades de tempos e espaços entrecruzados da vida indígena e não indígena. A terceira mostra as ressignificações socioculturais do povo Karajá de Aruanã.

\section{Configuração atual do território indígena Karajá}

O povo indígena Karajá se autodenomina Iny, cujo significado é "nós", "nós mesmos". O nome Karajá é de origem Tupi, cujo significado aproxima-se de "macaco grande" (ISA, 2015). De acordo com Rodrigues (2012), pertencem ao tronco linguístico Macro-Jê e dividem-se em três línguas: Karajá (GO/MT), Javaé e Xambioá (TO).

Segundo dados do IBGE (2010), o povo Karajá soma aproximadamente 3.000 índios e vive em cerca de 29 aldeias espalhadas ao longo do vale do rio Araguaia e afluentes. O maior quantitativo de aldeias localiza-se na Ilha do Bananal, estado do Tocantins. Toral (1992) afirma que, historicamente, as maiores aldeias tinham em torno de 400 pessoas com famílias extensas e que o número médio de moradores por casa era de aproximadamente 08 pessoas.

Conforme Salera Júnior; Malvasio e Giraldin (2006), as aldeias dos subgrupos Karajá e Xambioá estão às margens do Araguaia; as dos Javaé ficam às margens do rio Javaés, um braço menor do rio Araguaia, que contorna a parte leste da Ilha do Bananal, no Tocantins.

Com o contato interétnico e a convivência cada vez mais acentuada com os não-indígenas, o povo Karajá, segundo Toral (2002), sofreu diversas mudanças culturais, redução demográfica e processos migratórios entre os três subgrupos. Portanto, apesar das mudanças e do contato intenso, Lima Filho (1994), considera que a maioria das aldeias Karajá na Ilha do Bananal mantém seus costumes tradicionais como a língua materna, pescarias familiares, rituais como a dança de Aruanã e da casa grande (Hetohoky), plumárias, cestaria, artefatos em madeira e pinturas corporais.

A presente pesquisa é referente ao povo Karajá que vive no Estado de Goiás, município de Aruanã. De acordo com dados da SESAI/Aruanã (2016), somam aproximadamente 361 pessoas, distribuídas em duas aldeias, denominadas Buridina (160 pessoas) e Aricá ou BdèBure (85 pessoas), além dos 116 índios desaldeados. 
Eles estão distribuídos em três Terras Indígenas todas homologadas. A figura 01 mostra o mapa de espacialização das terras.

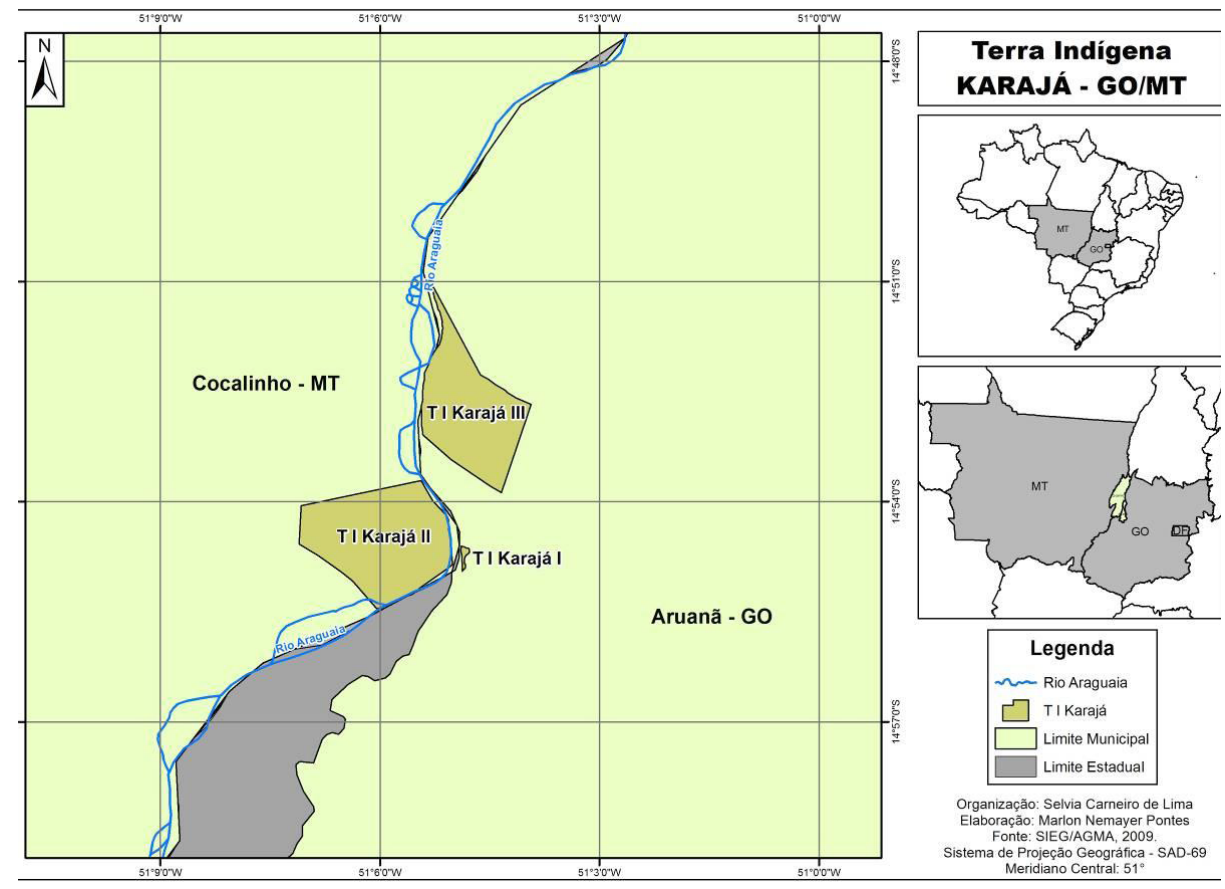

Figura 01. Terra Indígena do povo Karajá de Aruanã/GO.

Fonte: LIMA, Sélvia Carneiro de, 2009.

A aldeia Buridina, localiza na Terra Indígena Karajá I - TI, situada no centro da cidade de Aruanã, com 14 hectares e BdéBure, a mais recente delas, construída na Terra Indígena Karajá III - TIII. Há ainda uma terceira área, a Terra Indígena Karajá II - TII, localizada no município de Cocalinho-MT.

A TI II situa-se no estado do Mato Grosso, na margem oposta da TI I, e apresenta 893 hectares. Constitui-se área de caça, pesca e coleta atividades muito importantes para alimentação e produção material desse povo. Apresenta restrição de uso ao longo do ano em função do alagamento provocado pelo período chuvoso.

Apesar da conquista legal em relação à demarcação e homologação das Terras Indígenas dos Karajá de Aruanã, é necessário salientar a característica de fragmentação e restrição do território tradicionalmente ocupado por este povo, já mencionado em 1986, nos estudos de Pechincha e Silveira (p.21).

Em relação à questão territorial, é destacada a situação de cerceamento que limitou a aldeia por todos os lados, com evidente redução de seu espaço original, sendo destacado que "os índios de Aruanã não possuem nenhum documento que lhes garanta a propriedade da terra que então habitam, sendo esta apenas 
'respeitada'. Segundo as relatoras, "a não reivindicação das áreas vizinhas antes por eles habitada parte de uma consciência a nível comunitário de sua impotência frente à sociedade envolvente, já que reconhecem a dificuldade em reaver a área que lhes foi expropriada".

Desse modo os estudos de Lima (2010a, p.12), evidenciam os prejuízos sociais e culturais advindos desta redução do território tradicional, as áreas de cercamento.

A redução do território Karajá as três áreas demarcadas; a coleta da matériaprima para a produção artesanal tem sido cada vez mais difícil em função da degradação ambiental instalada no município e pela restrição imposta pela propriedade privada e pela própria delimitação do território de vivência impostos a eles; o crescimento da população indígena, o que implica a insuficiência do território para a sobrevivência de todos; o desmatamento intenso já existente principalmente na terra III, anterior a demarcação; os alagamentos que ocorrem nas Terras II e III que inviabilizam o plantio de roças e coleta na maior parte do ano e as atividades do turismo, que "invade" e reorganiza a vida indígena.

Além disso, o elemento central para a vida dos Karajá de Aruanã, o rio Araguaia, é também o elemento essencial para a existência da atividade turística nessa região, principalmente, com a formação das praias que atraem turistas para o descanso e lazer.

Neste sentido, com suas terras pressionadas por atividades econômicas vinculadas à pecuária e ao turismo, os Karajá procuram fortalecer sua cultura diante de inúmeras pressões externas exercidas pela própria situação de contato interétnico. A ressignificação da cultura parece ser um traço que evidência estratégias desse povo para afirmarem sua etnicidade negociando com a sociedade envolvente elementos culturais e objetos tecnológicos que vão sendo utilizados nos próprios termos dos indígenas de acordo com seus interesses.

Entre tradição e modernidade aparece a dualidade de tempos e espaços que marcam e mesclam os mundos da tradição indígena e dos não-indígenas.

\section{A dualidade de tempos e espaços}

Como atesta o mito de origem Karajá, o rio Araguaia constitui-se o eixo de referência mitológica social e cultural desse povo. É deste rio e de suas espécies que vem grande parte do sustento material e físico dos Karajá e seu curso tem firmado o povo onde estão até os dias de hoje (LIMA, 2010a).

Sobre os Karajá de Aruanã, Lima (2010b, p. 11) ressalta que as múltiplas relações com o rio vão aos poucos construindo as diversas relações identitárias presentes no modo de vida indígena. Por isso, "mais que sustento, o rio Araguaia representa para eles, a origem do povo e a extensão da própria vida e o mito de origem Karajá, aponta um vínculo forte entre território e cultura, território e produção da vida."

Portanto, com as intensas relações entre indígenas e não-indígenas, as ressignificações culturais são inevitáveis, ou seja, as mudanças socioculturais no que diz respeito à cultura e os elementos que a compõem como alimentação, rituais, língua, alimentação, dentre outros, são presentes na realidade desse povo e intensificadas pelas atividades econômicas da pecuária e do turismo e a inserção de novas tecnologias. 
Desse modo, o "fascínio" exercido pelas tecnologias, como o televisor, computadores, celulares, videogames; os casamentos interétnicos e os desejos suscitados pelas trocas comerciais adentram a vida indígena e fragiliza muitas vezes, elementos da tradição e cultura dos Karajá.

Aos poucos, a medida que o município de Aruanã foi se consolidando e atraindo novos moradores, o vestuário, os automóveis, a alimentação, os aparelhos eletrônicos, os eletrodomésticos, as normas de convivência, as regras de trânsito, os modismos, as músicas e danças dos não-indígenas, chegaram à aldeia, criando um cenário de ressignificações e transformações socioespaciais, introduzindo novos símbolos e valores, crenças e costumes, que entrecruzam a vida indígena ditando novos hábitos e maneiras de viver, impondo novas relações de tempo e espaço entre as gerações como evidenciará o texto que segue.

\section{Ressignificações socioculturais na vida indígena do povo Karajá de Aruanã}

A luta para permanecer em seus territórios originais sempre foi árdua na vida dos povos indígenas do Brasil. E mesmo o art. 231 da Constituição Federal de 1988 ao afirmar que: "São reconhecidos aos índios sua organização social, costumes, línguas, crenças e tradições, e os direitos originários sobre as terras que, tradicionalmente, ocupam", eles vivem historicamente pressionados por diferentes interesses econômicos, sendo seus territórios ainda hoje, foco de diversas disputas por parte de atividades e megaprojetos de mineração, agronegócio, produção de energia, turismo, pesca e caça ilegal; extração de madeira e de biodiversidade, biopirataria, construção de estradas e rodovias, entre outras formas de exploração.

O povo indígena Karajá que vive no município de Aruanã, está na porta de entrada para o Vale do Araguaia, região delimitada pela Secretaria de Estado e Desenvolvimento do Turismo de Goiás (2016), e tem como principais atrações turísticas a piscosidade de suas águas, diversos lagos e os meandros do rio Araguaia que compõem com suas praias, um dos mais belos cartões postais do Brasil. De acordo com Nunes (2013, p. 05):

O Rio Araguaia, em diversos locais ao longo de sua calha, atrai um imenso fluxo de turistas interessados nas belezas naturais do rio, tanto para descanso e lazer como para a pesca esportiva. No período da seca o nível da água baixa, deixando à mostra grandes praias de areia branca.

Aruanã é provavelmente a cidade na beira do Araguaia onde o turismo é mais intenso. Há inúmeras pousadas, hotéis, e mansões de veraneio, algumas delas voltadas para um turismo de luxo, com diárias que chegam a custar cerca de 350.00 reais. Durante o mês de julho, a prefeitura da cidade promove a Temporada Turística de Aruanã, oferecendo shows gratuitos à população e aos visitantes todas as noites de sexta-feira e sábado durante esse mês. Índios e regionais se referem a essa época simplesmente como temporada. A prefeitura estima que, só no mês de julho, mais de 600.000 pessoas passem pela cidade que, segundo o último censo, conta apenas 7.496 pessoas. Outros períodos, como o carnaval, feriados, o aniversário da cidade e o mês de maio (quando os cardumes que sobem o rio anualmente estão passando pela região), também atraem turistas para Aruanã, embora em quantidade muito menor que na temporada. 
Além das atividades do turismo o município de Aruanã conforme Silva (2013) está localizada na zona de influência da Estrada do Boi, onde os municípios vizinhos, historicamente, exibem vocação para a atividade pecuária e apresentam um dos maiores rebanhos do estado. Essa é uma afirmação constatada ao observar os dados do IBGE (2014) onde o município apresentou o maior rebanho da região com cerca de 246.000 cabeças de gado.

Desse modo, considera-se que o turismo e as atividades da agropecuária são as atividades que mais interferem na vida e território indígena Karajá. A atração da paisagem pelo consumo do lugar não deu ao povo Karajá escolha no que tange a decisão de participar ou não do afluxo turístico que marca Aruanã. Sem muito planejamento, os investimentos foram chegando, pousadas foram construídos, hotéis, casas, chalés, restaurantes e vários outros atrativos.

Nas margens do rio Araguaia, sobretudo, no mês de julho, mês da alta temporada, por corresponder ao período de férias escolares em Goiás, é possível encontrar um grande fluxo demográfico nos condomínios, casas e acampamentos, praças, restaurantes, bares, ruas e muitos ranchos ao longo do rio. Sobre as atividades da agropecuária e do turismo Nunes (2013, p. 05) considera que:

É peculiar especialmente, a situação de cerceamento territorial que a comunidade vive, após ter sido a aldeia, primeiramente, comprimida pelas frentes de expansão agropastoris em meados do século XX, e posteriormente, pelos investimentos turísticos ocorridos a partir da década de 1980 na cidade de Aruanã, sendo que hoje, diversas pousadas, guarda-barcos, hotéis e casas de veraneio circundam a aldeia. As praias e ruas ficam lotadas de turistas durante a temporada de julho e feriados, alterando drasticamente o cotidiano e a sustentabilidade da comunidade

De acordo com Portela (2006, p.83):

A paisagem da cidade foi bastante alterada na década passada (1990), já que além dos acampamentos de férias, surgiram condomínios onde foram construídas casas de veraneio que apresentam um padrão arquitetônico que se distingue da maioria das residências tradicionais em Aruanã (com muros altos, piscinas, jardins imponentes, cercas elétricas etc.), "empurrando" vários moradores antigos para a periferia da cidade. Com o crescimento do município, a aldeia de moradia da comunidade Karajá foi gradativamente limitada, sendo cerceada pelas construções urbanas [inclusive dentro da terra indígena posteriormente demarcada, existem dez casas de veraneio e uma escola estadual], estando a aldeia hoje, localizada no centro da cidade de Aruanã, ao lado do porto principal e entre as duas maiores avenidas da cidade.

Conforme pesquisas de Lima (2010b) na intensa ocupação dos espaços pelo turismo, a TI não foi poupada ao lado da aldeia Buridina, a área do cemitério tradicional também foi solapada pelo interesse mercadológico. Sobre ele foi construído, sem autorização dos indígenas, um guarda-barcos. Há ainda, escola, ruas e casas construídas e ocupadas dentro dos limites desta Terra. 
No período de alta temporada há presença de acampamentos provisórios dentro da Terra II, que corresponde à formação da praia mais próximo ao centro da cidade. No entanto, problemas relacionados ao turismo já eram evidenciados no relatório de Fagundes (1986, p. 1,2).

A cidade é essencialmente turística, trazendo com isso, sérios problemas de toda ordem à comunidade. Os índios vivem em estado de completa carência financeira. Não há o mínimo de princípio higiênico [. . . ] A bebida alcoólica que é usada em grande escala, tem sido um dos maiores males entre os índios. A promiscuidade é grande, a ociosidade é bem maior devido à falta de oportunidade de trabalho [. . .] Vivem juntos, comprimidos em uma área de $560 \mathrm{~m}^{2}$, o que é lamentável, não havendo espaço sequer para uma horta comunitária. É realmente humilhante o estado em que vivem os índios daquela área. Devido ao contínuo uso de bebida alcoólica, os homens, com duas exceções, vivem caídos pelas praças e sargetas. É um quadro chocante, a miséria e a fome dominam os seus lares.

Desse modo, as conquistas legais não se concretizaram em conquistas efetivas na garantia dos direitos territoriais dos Karajá. Interesses econômicos continuam usurpando o direito à vida e prejudicando o uso dos territórios indígenas em Aruanã e as ressignificações socioculturais são intensificadas nestas relações.

Roque Laraia (2001) afirma que a cultura é dinâmica, pois sofre alterações ao longo do tempo. Essas mudanças culturais resultam de influências internas ou externas. O processo que envolve tais mudanças é considerado nesse estudo como ressignificação, que pode ser tanto espacial como sociocultural.

Segundo Lippi (1990) ressignificação é dar novo significado, atribuindo novo sentido a uma experiência ou palavra, é o processo de atribuir novo sentido ou significado as coisas que a nós ou aos outros acontecem.

Neste viés, acredita-se que as questões identitárias, culturais e simbólicas que moldam as características mais íntimas de um povo, pode sofrer ressignificações em distintos tempos e espaços históricos. Para Haesbaert, (1999, p. 178)

[...] a identidade social é também uma identidade territorial quando o referente simbólico central para a construção desta identidade parte do ou transpassa o território. Nesse cenário, as identidades se situam frente ou num espaço simbólico, social/historicamente produzido.

Para Sahlins (1997) a cultura é uma síntese de estabilidade e mudança, de passado e presente, de diacronia e sincronia. Toda mudança também é reprodução cultural. Nesse contexto, Lima (2010), considera que a cultura indígena Karajá pelo intenso contato interétnico encontrou o caminho da ressignificação da cultura mesclando elementos da modernidade e da tradição indígena.

Nos trabalhos de campo realizados em 2014, 2015 e 2016, constatou-se alguns elementos socioculturais que foram ressignificados, modificados e ou substituídos na vida indígena do povo Karajá de Aruanã, sobretudo, nas últimas décadas, como mostra o Quadro 01: 
Quadro 01. Elementos ressignificados, modificados e ou substituídos na vida indígena do povo Karajá de Aruanã

\begin{tabular}{|c|c|c|}
\hline Elementos & Antes do contato & Atualmente \\
\hline Língua & Inyrybe. & Português e Inyrybe. \\
\hline Casamento & Apenas entre indígenas. & Entre não indígenas. \\
\hline Alimentação & Caça, pesca e coleta. & $\begin{array}{l}\text { Predomínio de alimentos industrializados como } \\
\text { sal, açúcar, café, óleo, bolachas, margarina, doces, } \\
\text { enlatados, etc. }\end{array}$ \\
\hline Vestuário & Plumárias; cocar; adornos variados. & Roupas, calçados, maquiagens e adornos. \\
\hline Música & Tradicional Karajá. & $\begin{array}{l}\text { Músicas em língua portuguesa e estrangeira de } \\
\text { estilos variados, como Funk, Sertanejo, Forró, etc. }\end{array}$ \\
\hline Pintura & $\begin{array}{l}\text { Tintas elaboradas com elementos } \\
\text { naturais: frutas, sementes, cinza, } \\
\text { entre outros; grafismos que imitam, } \\
\text { sobretudo, a fauna. }\end{array}$ & $\begin{array}{l}\text { Atualmente as pinturas tradicionais Karajá são } \\
\text { bastante utilizadas como elemento de troca com } \\
\text { os turistas. Há uma preferência, sobretudo pelas } \\
\text { gerações mais jovens pelas tatuagens em detrimento } \\
\text { das pinturas corporais tradicionais. }\end{array}$ \\
\hline $\begin{array}{l}\text { Relações } \\
\text { familiares }\end{array}$ & $\begin{array}{l}\text { Respeito aos mais velhos e } \\
\text { liderança indígena; reuniões para } \\
\text { tratarem sobre decisões referentes } \\
\text { à comunidade; aprendizagens sobre } \\
\text { a cultura com os mais velhos e com } \\
\text { os pais por meio de história oral, } \\
\text { narrativas e mitos; predomínio dos } \\
\text { interesses coletivos. }\end{array}$ & $\begin{array}{l}\text { Os jovens tem pouco tempo com a família; muitos } \\
\text { não respeitam mais as lideranças e os mais velhos } \\
\text { da aldeia; as crianças quase não se interessam } \\
\text { pelas histórias orais, narrativas e mitos e preferem } \\
\text { assistirem televisão e ver desenhos; as questões } \\
\text { individuais estão se sobrepondo aos interesses } \\
\text { coletivos. }\end{array}$ \\
\hline Crenças & $\begin{array}{l}\text { Nos elementos da natureza: peixe, } \\
\text { terra, água, etc.; nos espíritos dos } \\
\text { Aruanãs Xamanismo. }\end{array}$ & Catolicismo, protestantismo. \\
\hline Saúde & $\begin{array}{l}\text { Uso de plantas e de rituais de cura; } \\
\text { consulta e orientação do curador e ou } \\
\text { do pajé. }\end{array}$ & Uso de remédios industrializados. \\
\hline Bebidas & $\begin{array}{l}\text { Calugi (bebida tradicional feita de } \\
\text { mandioca ou milho). }\end{array}$ & $\begin{array}{l}\text { Bebidas com teor alcoólico como aguardente e, } \\
\text { cerveja, sucos, refrigerantes. }\end{array}$ \\
\hline Costumes & $\begin{array}{l}\text { Práticas de resguardo no nascimento } \\
\text { de bebês, principalmente dos } \\
\text { homens; nominação - hierarquia dos } \\
\text { nomes dos antepassados; casamento } \\
\text { intraétnico. }\end{array}$ & $\begin{array}{l}\text { O resguardo pós-nascimento é pouco praticado; } \\
\text { os nomes indígenas estão sendo substituídos por } \\
\text { nomes não-indígenas e a tradição em manter os } \\
\text { nomes familiares está em desuso; os casamentos } \\
\text { interétnicos tem tido predomínio, sobretudo, com } \\
\text { não indígenas. }\end{array}$ \\
\hline Moradia & Oca de palha ou tapiri. & Casas de tijolos e lajes. \\
\hline Trabalho & $\begin{array}{l}\text { Roças tradicionais; criação de } \\
\text { abelhas; colheita do mel; fabricação } \\
\text { de rapadura; caça, pesca e coleta. }\end{array}$ & $\begin{array}{l}\text { Vendedor; recepcionista; lavador de carro; operador } \\
\text { de caixa; barqueiro. }\end{array}$ \\
\hline
\end{tabular}

Fonte: Trabalhos de campo realizado nas aldeias Karajá de Aruanã-GO - 2014/2015/2016.

Os elementos e dados apresentados no quadro 01 , foram levantados no decorrer dos trabalhos de campo em conversas e entrevistas realizadas com algumas lideranças e famílias Karajá. A estadia na aldeia foi curta, ao todo foram realizados seis trabalhos de campo, dois em 2014, dois em 2015 e dois em 2016, com duração de aproximadamente quatro dias cada um. 
Compreende-se que os dados levantados e investigados foram pouco exploradas do ponto de vista da análise, pois, as informações, sobretudo, referente aos costumes tradicionais são ainda restritas e ou pouco evidenciadas nas falas dos Karajá pesquisados. Portanto, é a princípio uma fotografia das diversas ressignificações socioculturais vivenciadas por esse povo. A respeito dos casamentos interéticos Nunes (2009, p.07), considera que

Na década de 1970, como dito acima, teve início a mestiçagem. Algumas décadas depois, podemos perceber que um dos resultados deste processo foi a instauração de um novo padrão de casamentos. Desde então, as uniões entre dois indígenas é rara e, geralmente, fruto de particularidades das histórias pessoais: o normal, poder-se-ia dizer, é casar com tori. Dessa forma, a grande maioria dos atuais casamentos $(77,8 \%)$ envolve um cônjuge não-indígena. Sendo, portanto, a mestiçagem uma questão tão ampla e importante nesta aldeia, como os Karajá conceitualizam este processo?

Em uma das entrevistas realizadas com os Karajá referente a questão dos casamentos interétnicos, sobretudo, com não-indígenas é revelado uma situação de conflito geracional pelas escolhas predominantemente misturadas ${ }^{1}$.

Os jovens principalmente não respeitam mais a tradição, não querem casar mais com Karajá preferem as pessoas de fora, casam de qualquer jeito, não respeitam os nomes tradicionais, nem nossos costumes, tudo mudado, tudo misturado e não tem nem conversa mais, vai é sempre aumentar.

É sabido que as mudanças socioculturais são intensas, vão além dos dados apresentados no quadro 01, e apresentam-se interconectadas, uma vez que a modificação em um elemento cultural gera modificações em outros traços culturais, como, por exemplo, o impacto da televisão ao capturar as crianças fora das rodas de contação de história, elemento essencial nas culturais de tradição oral, para o processo educativo. Portanto, o enfraquecimento da história oral na aldeia, reflete na compreensão das gerações sobre sua própria história, o interesse pelo uso e compreensão da língua materna do povo ao qual pertence.

Dentre as diversas modificações culturais apresentadas, o atual cacique da aldeia Buridina destacou que a língua indígena está sendo a mais impactada, aproximadamente, $20 \%$ dos Karajá não utilizam mais a língua materna para comunicar-se. Situação retificada por um dos indígenas entrevistados que afirmou (2015): "De toda mudança, a língua indígena é a que mais está acabando, jovem não quer fala língua de índio e fica falando português e acha bonito e ensina seus filhos e língua indígena vai se acabando".

$\mathrm{Na}$ investigação feita por Nunes (2009. p.04), a impressão dos não-indígenas quanto ao povo Karajá é de que

[...] o mundo dos tori não está apenas na cidade e, num certo sentido, Buridina é também parte da cidade. Os Karajá comem nossas comidas, estão integrados ao comércio local, usam nossas roupas, nossa língua, nossos nomes, têm

1. Ver trabalho de Nunes (2009) 
televisões, telefones, fogões, geladeiras, freezeres, bicicletas, algumas motos, camas, guarda-roupas, barracas de acampamento, canoas de alumínio com motores de popa, etc. Além do fato de terem muitos amigos não-indígenas na cidade e, sobretudo, filhos com eles. Hoje os Karajá de Buridina se dizem misturados, classificando àquelas crianças resultantes desses casamentos como mestiços, termos também usados pelos brancos para se referir a eles. Uma aldeia incrustada no centro da cidade, habitada por índios "aculturados", em sua maioria mestiços, que levam uma vida de branco. Para a maioria dos moradores e visitantes de Aruanã, a aldeia é apenas mais um bairro da cidade e os índios pouco se diferenciam deles.

Se o peixe, a tartaruga, a pesca, a coleta, o mel, o arco, a flecha, a pintura, os nomes, as danças, os rituais, as músicas, entre tantos outros, são elementos importantes para a alimentação e cosmologia dos Karajá já não são tão praticados como no passado. Há indícios de pesca predatória para a comercialização dos peixes; a prática de cultivo de roças está cada vez mais remota e os hábitos alimentares tradicionais estão obsoletos fortalecendo a ocorrência de doenças relacionadas ao consumo de alimentos industrializados. Acentua-se problemas com drogadição, alcoolismo, violência, prostituição e o descarte de resíduos sólidos na aldeia aumentando, consideravelmente, a poluição visual e do solo pelos dejetos acumulados.

Porém, mesmo diante de pressões externas, das atividades econômicas advindas da pecuária e do turismo há estratégias de enfrentamento para a manutenção identitária dos Karajá de Aruanã, e as ressignificações de diversos elementos de sua cultura, parecem apontar para estratégia de inserção no capitalismo sem perderem suas raízes identitárias.

Por não apresentarem possibilidades de escolha sobre a incidência ou não do turismo em seus territórios tradicionais, adotaram estratégias de negociação e adaptação de seus conhecimentos para atender a lógica imposta por essas atividades e utilizar do potencial turístico para o sustento de suas famílias. Nesse contexto, os artefatos indígenas, passam a serem produzidos e comercializados como artesanato, constituindo-se uma das atividades essenciais para a subsistência desse povo.

Conforme relato do atual cacique da aldeia Buridina: "Além de visitar a aldeia, os turistas sempre interessaram pelo artesanato, foi ai que descobrimos o potencial de nossas peças e nosso trabalho como uma atividade econômica rendável." Para Portela (2006, p.190):

[...] se o comércio trouxe o impulso necessário para que se retomasse a produção do artesanato tradicional entre os Karajá de Aruanã, este acontecimento não ocorreu somente por uma necessidade de sustentabilidade econômica, sendo, sobretudo, um momento de recriação da memória coletiva através dos recursos simbólicos presentes na produção artesanal.

Entre as peças mais procuradas pelos turistas estão às bonecas Karajá denominadas na língua indígena de Ritxoko, como mostra a figura 03 . 


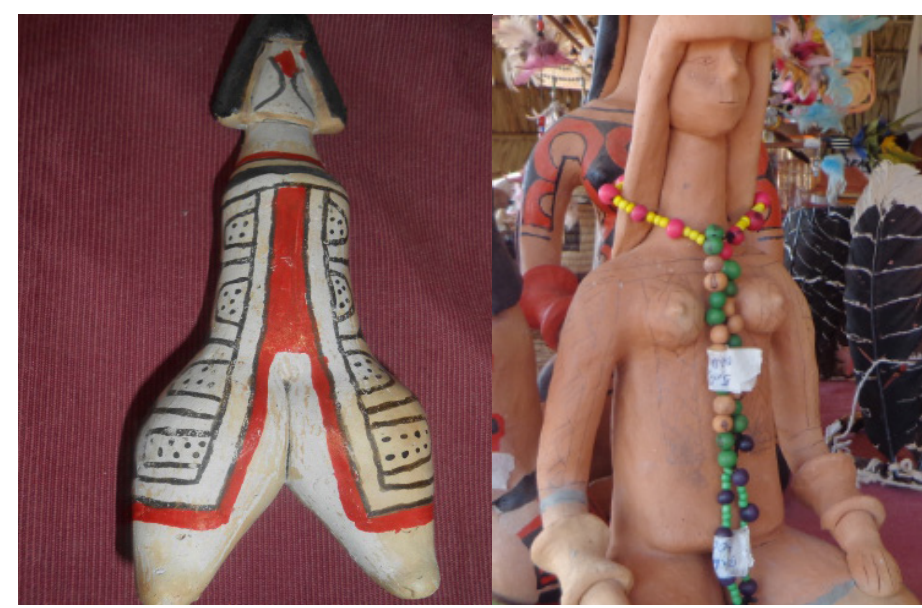

Figura 03. Boneca Ritxoko.

Fonte: SILVA, Lorranne Gomes da (2014)

As bonecas foram tombadas pelo Instituto do Patrimônio Histórico e Artístico Nacional (IPHAN), em 2012, como patrimônio cultural brasileiro. A atividade é exclusiva das mulheres que utilizam a confecção para transmitirem ensinamentos referentes a cultura indígena para as crianças. Tradicionalmente feitas sem membros superiores e inferiores, aqui há um importante traço de ressignificação cultural para adequação ao mercado, como nos revela um dos indígenas entrevistado.

Para atender o gosto dos turistas as bonecas Karajá foram readequadas e receberam modificações quanto ao tamanho (tornaram-se maiores); ganharam braços e pernas e depois das modificações feitas nas bonecas as vendas aumentaram (ARUANÃ/JULHO, 2014).

Em 2015 a venda do artesanato contribuiu para o sustento de, aproximadamente, 30 famílias direta e indiretamente. O Museu Maurehi, localizado na entrada da aldeia Buridina e a Associação Família Tehaluna Wassuri são locais essenciais para a confecção e comercialização das peças produzidas. Conforme Portela (2006, p.187), o projeto Mauheri que possibilitou a criação da escola indígena e do museu:

É importante observar que o Projeto Maurehi se constitui como elemento agregador da auto identificação Karajá em Buridina, não por suas características de "solução" aos problemas da comunidade, mas sim, por aglutinar os "traços diacríticos" anteriormente "selecionados" pela comunidade: a língua materna e a produção artesanal

Os Karajá em parcerias diversas com a Universidade Federal de Goiás (UFG); Universidade Estadual de Goiás (UEG), Secretaria de Estado de Educação, Cultura e Esporte de Goiás (SEDUCE), Fundação Nacional do Índio (FUNAI), Fundação Nacional de Saúde (FUNASA), dentre outras, tem procurado fortalecer a relação entre as gerações a fim de revitalizar os conhecimentos tradicionais do povo e através da Educação Escolar 
Indígena, tem empreendido esforços para fortalecer o uso da língua indígena Karajá e de elementos da cultura material e imaterial.

Há atividades de conscientização na escola que trata de assuntos como à pesca predatória; a preservação de espécies silvestres como peixes e tartarugas; o incentivo as formas adequadas de coletas; conscientização do descarte correto de resíduos sólidos.

Assim, os Karajá continuam lutando há séculos para manterem-se vivos defendendo a identidade outrora estabelecida como o Povo das águas, ao permanecerem as margens do seu rio-materno, o Behoroky, em tempos de incessantes avanços contra os povos originários, nas diversas aprovações de projetos e atividades econômicas que caracterizam retrocesso contra os povos indígenas no Brasil.

\section{Considerações Finais}

São várias as problemáticas acerca das questões indígenas, sobretudo, os conflitos pelo território que perduram até hoje. No caso dos Karajá de Aruanã a pressão econômica advém das atividades sobretudo, do turismo e da pecuária em suas terras.

As ressignificações socioculturais diagnosticadas nessa pesquisa mostra que apesar de ter sido inevitável o convívio com os não-indígenas, essa convivência reorganizou valores entre os Karajá, promoveu conflitos advindos das pressões de interesses externos entre gerações, e modificou elementos essenciais da cultura indígena, como o uso da língua Karajá.

No entanto, a presença atual dos Karajá as margens do Araguaia revelam um povo que tem resistência cultural, histórica e geográfica para permanecerem as margens de seu rio de vida: o Araguaia.

E apesar das intensas mudanças, do processo contínuo de transformação, de tensão provocada pela articulação entre tradição e inovação, a cultura indígena Karajá continua sendo fortalecida permanentemente recriando a tradição, introduzindo novos sentidos e novos símbolos como as bonecas Ritxoko (patrimônio da humanidade) que para atender as demandas do turismo foram modificadas, alterando o sentido para o qual foram criadas adaptando-se ao gosto dos turistas.

\section{$* * *$}

Este artigo é produto da pesquisa intitulada "Reconfigurações culturais no modo de vida indígena: o povo Karajá do Cerrado Goiano”, realizada no âmbito da Universidade Estadual de Goiás - Câmpus Quirinópolis (vigência entre 2014 à 2017).

$* * *$

\section{Referências}

CONSTITUIÇÃO FEDERAL BRASILEIRA. http://www.planalto.gov.br. Acesso: 22/02/2016. 
HAESBAERT, Rogério. Concepções de território para entender a desterritorialização. In (Org.) Territoriais. In: ROSENDAHL, Z. CORRÊA, R. L. Manifestações da cultura no espaço. Rio de Janeiro: UERJ, 1999.

FAGUNDES, Jeorgino Martins. Área indígena Aruanã Brasília: FUNAI, outubro/ 1986. IBGE. Senso Demográfico (2010). Acesso: 22/02/2016.

IBGE. Cidades. (2014). http://www.cidades.ibge.gov.br. Acesso: 22/02/2016.

LARAIA, Roque de Barros. Cultura: um conceito antropológico. 14 ed. Rio de Janeiro: Jorge Zahar Ed., 2001.

LIMA, Sélvia Carneiro de. Mapa das Terras Indígenas de Goiás. In: A permanência do estranho: os Karajá, os Tori e as disputas territoriais do cerrado goiano. Dissertação (Mestrado em Geografia). Universidade Federal de Goiás. Instituto de Estudo Socioambientais. Goiânia, 2010a.

. Os Karajá de Aruanã/GO e seus Territórios Restritos: biodiversidade reduzida, integridade abalada. Ateliê Geográfico. Edição Especial Goiânia-GO v. 4, n. 1, p.84-115, 2010b.

LIMA FILHO, M. F. Hetohoky: um rito karajá. Goiânia: Editora UCG, 1994.

LIPPI, J. R. S. Terapia Cognitiva da Família. São Paulo, Editora: Biogalênica, 1990.

NUNES, Eduardo S. A cruz e o itxe (k)ò: mestiçagem, mistura e relação entre os Karajá de Buridina (Aruanã - GO). Monografia. Departamento de Antropologia, Universidade de Brasília, 2009.

. O território das onças e a aldeia dos brancos: lugar e perspectiva entre os Karajá de Buridina (Brasil Central), 2012.

PECHINCHA, Mônica; SILVEIRA, Ester. Relatório de viagem à Aldeia Indígena Karajá de Aruanã. Brasília: FUNAI, 1986.

PORTELA, Cristine de Assis. Nem ressurgidos, nem emergentes: a resistência histórica dos Karajá de Buridina em Aruanã-Go (1980-2006). Dissertação. Faculdade de Ciências Humanas e Filosofia da Universidade Federal de Goiás, 233 páginas, 2006.

RODRIGUES, Aryon D. "Macro-Jê". In R. M. W. Dixon and Alexandra Y. Aikhenvald (eds.), The Amazonian Languages. Cambridge Language Surveys. Cambridge: Cambridge University Press, 1999.

TORAL, André Amaral de. Cosmologia e sociedade Karajá. Rio de Janeiro: UFRJMuseu Nacional, (Dissertação de Mestrado, 414p), 1992.

SALERA JÚNIOR, Giovanni; MALVASIO, Adriana; GIRALDIN, Odair. Relações cordiais. Ciência Hoje, 39 (226): 61-63. 2006.

SAHLINS, M. Ilhas da História. Rio de Janeiro: Zahar, 1997.

SILVA, Elaine Barbosa da. A dinâmica socioespacial e as mudanças na cobertura e uso da terra no bioma Cerrado. 148 f. Tese (Doutorado em Geografia). Universidade Federal de Goiás, 2013. 
SECRETARIA DE TURISMO DO ESTADO DE GOIÁS. http://www.goiasturismo. go.gov.br. Acesso: 22/02/2016.

SESAI. Secretaria Especial da Saúde Indígena. Posto local da cidade de Aruanã/GO, 2016.

\section{LORRANNE GOMES DA SiLVA}

Mestre e Doutora em Geografia pela Universidade Federal de Goiás. Professora do curso superior de Tecnologia e Gestão de Turismo da Universidade Estadual de Goiás, câmpus Cora Coralina, Cidade de Goiás.

Rua Ari Bento Xavier, quadra 04, lote 12, Panorama Parque, Inhumas/Goiás, CEP:75400-000

E-mail: lorrannegomes@gmail.com

Sélvia Carneiro de Lima

Mestre e Doutora em Geografia pela Universidade Federal de Goiás.

Professora de Geografia do Instituto Federal de Educação, Ciência e

Tecnologia de Goiás - Câmpus Inhumas.

Rua Cerejeiras, número 351, Jataí, Goiás, CEP: 75806355

E-mail: selvia_lima@yahoo.com.br

Recebido para publicação em dezembro de 2016 Aprovado para publicação em junho de 2017 